"This is the peer reviewed version of the following article: Rescue of injured motoneurones by grafted neuroectodermal stem cells: effect of the location of graft

Gholam Pajenda, Krisztián Pajer, Gábor Márton, Heinz Redl, Antal Nógrádi Restorative Neurology and Neuroscience 31 (2013) 263-274

DOI 10.3233/RNN-120294, which has been published in final form at DOI 10.3233/RNN-120294. This article may be used for non-commercial purposes in accordance with Wiley Terms and Conditions for Self-Archiving." 


\section{Rescue of injured motoneurones by grafted neuroectodermal stem cells: effect of the location of graft}

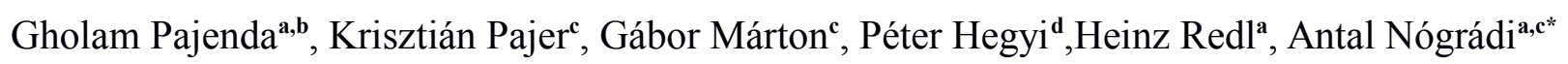

${ }^{a}$ Austrian Cluster for Tissue Regeneration and Ludwig Boltzmann Institute for Experimental and

Clinical Traumatology at the Research Centre for Traumatology of the Austrian Workers'

Compensation Board (AUVA), Donaueschingenstr. 13, A-1200 Vienna, Austria

${ }^{b}$ Department of Traumatology, Medical University of Vienna, Währinger Gürtel 18-20, A-1090

Vienna, Austria

${ }^{\mathrm{c} D e p a r t m e n t ~ O p h t h a l m o l o g y}$ and ${ }^{\mathrm{d}} 1$ st Department of Internal Medicine, Albert Szent-Györgyi

Clinical Centre, University of Szeged, Korányi fasor 10-11, H-6720 Szeged, Hungary

*corresponding author:

Antal Nógrádi

Laboratory of Neuromorphology

Dept. of Ophthalmology

Albert Szent-Györgyi Clinical Centre

University of Szeged

6720 Szeged

Korányi fasor 10-11.

Tel.: +36-62-545786

Fax: +36-62-546118

e-mail: nogradi.antal@med.u-szeged.hu 


\begin{abstract}
Avulsion of one or more ventral roots from the spinal cord leads to the death of the majority of affected motoneurons. In this study we investigated whether immortalized clonal neuroectodermal stem cells applied to the injured cord in various ways impart neuroprotection on motoneurons otherwise destined to die.
\end{abstract}

The lumbar 4 (L4) ventral root of Sprague-Dawley rats was avulsed and reimplanted ventrolaterally into the injured cord. Clonal neuroectodermal murine stem cells (NE-GFP-4C) were placed in fibrin clot around the reimplanted root, were injected immediately following avulsion into the reimplanted ventral root or directly into the L4 segment. Three months after the primary surgery the L4 motoneuron pool was retrogradely labelled with Fast blue and the numbers of reinnervating motoneurons were determined. Functional recovery was tested biweekly through the use of the CatWalk automated gait analysis system.

Transplantation of neuroectodermal stem cells into the reimplanted root or into the L4 spinal segment resulted in similarly extensive regeneration of the motoneurons $(671 \pm 26$ SEM $v s 711 \pm$ 14 SEM L4 motoneurons, respectively). In these groups significant functional recovery was achieved. The negative controls and animals with perineural stem cell treatment showed poor motor recovery and reinnervation ( $42 \pm 10 \mathrm{SEM} v s 65 \pm 2.5 \mathrm{SEM}$, respectively).

This study provides evidence that neuroectodermal stem cell transplantation into the reimplanted ventral root induces as successful regeneration of injured motoneurons as stem cells grafted into the spinal cord. 
Keywords: stem cell, spinal cord, ventral root, avulsion injury, motoneuron, cell death, functional reinnervation, survival

\section{Introduction}

Adult motoneurons survive if injury to their axons is inflicted relatively far from the cell body.

However, axonal injury applied close to the cell body, such as avulsion of one or more ventral roots induces the death of the vast majority of affected motoneurons (Carlstedt et al. 1993, 2000, Koliatsos et al. 1994, Nógrádi and Vrbová 2001, Nógrádi et al. 2007). Reimplantation of the lumbar ventral roots without auxillary treatment results in poor survival and regeneration of motoneurons (Carlstedt et al. 2000, Eggers et al. 2010, Nógrádi and Vrbová 1996, 2001). However, reimplantion of the avulsed root combined with treatment with the anti-excitotoxic compound riluzole (2-amino-6-trifluoromethoxybenzothiazole) rescued the majority of the injured motoneurons otherwise destined to die (Nógrádi and Vrbová 2001, Nógrádi et al. 2007, Pintér et al. 2010). Earlier studies have shown that riluzole not only prevented the death of the damaged lumbar and cervical motoneurons but enabled them to regenerate their axons into the reimplanted ventral root and thus provide functional reinnervation for the denervated limb musculature (Nógrádi et al. 2007, Pintér et al. 2010).

Several recent attempts, other than therapeutic efforts to reduce excitotoxicity to the damaged motoneurons have been made to rescue adult motoneurons following avulsion injury, including therapy with neurotrophic factors (Blits et al. 2004; Eggers et al. 2008, Haninec et al. 2003, Novikov et al. 1995; Wu et al. 2003), and progenitor and stem cell therapy (Hell et al. 2009, Su et al. 2009). In general, there are a great number of stem and progenitor cells that can be used in the CNS to induce neuronal survival, axon regeneration or replace missing cells. While many of these 
cell treatment strategies apply stem cells that bring little or not significant improvement in morphological restoration and in function, there are few therapeutic approaches where the applied cells are proven to be safe and effective at long term (Bottai et al. 2010, Steinbeck et al. 2011, for review see: Ruff et al. 2012).

Recent experiments performed in our lab oratory provided evidence that clonal murine neurectodermal stem cells, grafted into the injured rat spinal cord immediately after ventral root avulsion and reimplantation are able to promote the regeneration of approximately $65 \%$ of the injured motoneurons (unpublished data). The neuroectodermal stem cells (NE-GFP-4C cell line, ATCC No.: CRL-2936) were originally isolated from the forebrains of p53-deficient E9 mouse embryos and thoroughly characterised both in vitro and in vivo (Schlett et al. 1997, Hádinger et al. 2009). While the survival and differentiation of the grafted cells and the therapeutic mechanism how motoneurons are rescued and their regeneration is promoted, are described in detail (submitted manuscript, Pajer et al. 2012), it is not known whether neuroectodermal stem cells applied at locations other than into the spinal cord may be able to effectively rescue neurons otherwise destined to die. Transplantation of stem cells into a damaged spinal cord may further augment the extent of injury caused by the avulsion of one or more ventral roots and therefore it would be advantageous to find alternative routes of stem cell grafting which may provide favourable conditions for the morphological restitution of the damaged spinal segment.

The aim of the present study was to compare the therapeutic potential of the transplanted NE-GFP4C cells applied in topically different transplantation paradigms.

\section{Materials and methods}

\section{Maintenance of NE-GFP-4C stem cells}


The clonal neuroectodermal stem cells were isolated from 9-day-old forebrain vesicles of embryos of transgenic mice lacking the tumor suppressor gene p53 and they were made to produce eGFP as previously described (Schlett et al. 1997). The NE-GFP-4C stem cells (ATCC No.: CRL-2936) were maintained on nuncloned petri dishes (Invitrogen, Austria) in High glucose Dulbecco Modified Essential Medium (H-DMEM, Sigma, Austria) supplemented with 10\% fetal calf serum (FCS, Gibco BRL) at $37^{\circ} \mathrm{C}$ and $5 \% \mathrm{CO}_{2}$. Floating cells appeared after 3 days and were passaged every 2 days using trypsin digestion and mechanical dissociation. Medium was changed every day. All cell cultures underwent at least two but no more than five passages before transplantation.

\section{Ventral root avulsion-reimplantation and transplantation of NE-GFP-4C stem cells}

All together 48 female Sprague-Dawley rats (Animal Research Laboratories, Himberg, Austria, and Animal Facilities at the Faculty of Medicine, University of Szeged, weighing 180-220 g body weight) were used. Twenty-four animals were used for short-term survival studies ( 5 and 10 days of survival, 4 animals in each group, except control group), 20 rats survived for 3 months following the original operation ( $\mathrm{n}=5$ in each group) and 4 intact animals were used to determine the number of motoneurons in the intact L4 segment.

All the operations were carried out under deep ketamine-xylazine anaesthesia (ketamine hydrochloride: 90 mg/kg body weight, Ketavet, Pharmacia \& Upjohn Co.; xylazine: 5 mg/kg body weight, Rompun, Bayer Co.) and sterile precautions. To maintain the body temperature at $37.0 \pm 0.5^{\circ} \mathrm{C}$, the rats were kept on a heating pad during the surgery. Laminectomy was performed at the level of T13-L1 vertebrae, the dura was opened and the left L4 ventral root was pulled out leaving the dorsal roots intact. Then the cut end of the ventral root was inserted into the lateral part of the spinal cord. To avoid damage to the cord, a small hole was created on the lateral surface of the cord, and the avulsed root was inserted into the hole using a watchmaker's forceps (Dumont, 
Switzerland, No. 5). Special care was taken to avoid damage to the cord, including its motoneuron pool, or to the reimplanted root (Fig. 1A-B). Animals in group 1 served as controls: their L4 ventral root was avulsed and reimplanted but they received no stem cells. In group 2 animals the reimplanted root was surrounded by $3 \times 10{ }^{5}$ stem cells applied in a loose fibrin matrix (Baxter Ltd, Vienna, Fig. 1B). Group 3 animals received 3 injections of stem cells ( 5 x $10^{4}$ each) along a $3 \mathrm{~mm}$ length of the reimplanted root (Fig. 1C). The proximal injection was applied immediately at the reestablished ventral root-spinal cord junction zone, the second and the third injections were applied approx $1.5 \mathrm{~mm}$ from the junction zone and form the second injection site, respectively. Animals in group 4 (intraspinal grafting of stem cells) had $3 \times 10^{5}$ stem cells injected into the caudal part of the L4 segment (Fig. 1D).. The spinal cord was covered with the remaining dura, the wound was closed and the animals were allowed to recover (Nógrádi and Vrbová, 1996, 2001). Animals survived for 5 or 10 days or for 3 months. The experiments were carried out with the approval of the Animal Protocol Review Board of City Government of Vienna and with that of the Committee for Animal Experiments, University of Szeged and rules regarding the care and use of animals for experimental procedures were followed. All the procedures were carried out according to the Helsinki Declaration on Animal Rights. Adequate care was taken to minimize pain and discomfort.

\section{Retrograde labelling}

Operated animals that survived for 3 months ( $n=5$ in each group) and intact animals $(n=4)$ were deeply reanaesthetized as described above. On the left side the ventral ramus of the L4 spinal nerve was sectioned and the proximal stump of the nerve covered with few crystals of Fast Blue (FB; Illing Plastics GmbH, Breuberg, Germany). Five days after the application of the fluorescent dye the animals were reanaesthetized and perfused transcardially with $4 \%$ paraformaldehyde in $0.1 \mathrm{M}$ phosphate buffer $(\mathrm{pH}=7.4)$. 


\section{Immunohistochemistry}

Twenty-five $\mu \mathrm{m}$ thick transverse spinal cord sections and twenty $\mu \mathrm{m}$ thick longitudinal sections of the operated roots were cut on a cryostat (Leica CM 1850, Leica GmbH, Germany) and mounted onto gelatin-coated glass slides. Nonspecific binding sites were subsequently blocked with $1 \%$ milk powder solution. Primary antibodies were incubated overnight at $4{ }^{\circ} \mathrm{C}$, washed, and then incubated with fluorescent-conjugated secondary antibodies for $1 \mathrm{~h}$ at room temperature. The following primary antibodies were used: chicken polyclonal anti-green fluorescent protein (GFP; 1:2000, Millipore-Chemicon, Temecula, USA), rat monoclonal anti-mouse astrocyte surface antigen and rat anti-mouse neuronal surface antigen (M2 and M6, respectively, both from DSHB, Iowa University, USA, 1:100), mouse anti-murine stage-specific antigen-1 (SSEA-1, DSHB, Iowa University, USA, 1:100) anti-neurofilament 200kD (NF200, Abcam Ltd, 1:200, Cambridge, UK). Secondary antibodies were used as follows: Alexa Fluor 488 goat anti-chicken, Alexa Fluor 594 donkey antirat, Alexa Fluor 546 rabbit anti-mouse, Alexa Fluor 405 goat anti-rabbit (all from Life Technologies

Corporation, 1:400). Sections processed for choline-acetyltransferase

(ChAT) immunohistochemistry were preincubated in 3\% normal goat serum for $1 \mathrm{~h}$, then treated with a polyclonal goat anti-ChAT antibody (Millipore-Chemicon, Hofheim, Germany, 1:100) overnight at $4 \circ \mathrm{C}$. The immune reaction was completed by using the avidin-biotin technique (reagents were purchased from Vector Laboratories, Burlingame, CA), and finally were tyramide-amplified with the Alexa Fluor 546 TSA kit (Tyramide Signal Amplification; Life Technologies). Fluorescent signals were detected in an Olympus FX51 epifluorescence microscope equipped with a DP70 digital camera (Olympus Ltd, Tokyo, Japan). Confocal microscopic images were obtained by using an Olympus FluoView ${ }^{\circledR}$ FV10i compact confocal microscope. Digital images were resized and their contrast and brightness were adjusted. 


\section{Cell counts}

The number of retrogradely labelled cells was determined. To avoid double counting of the same neuron present in two consecutive sections, the retrogradely labelled neurons were mapped with the aid of an Olympus (Olympus Ltd, Tokyo, Japan) drawing tube, and their locations were compared to those of labelled neurones in the previous section (Nógrádi et al. 2007, Pintér et al. 2010). All sections from the L4 motoneurone pool were used.

\section{Analysis of locomotion pattern - CatWalk gait analysis}

To determine and analyze the parameters of the forelimb movement pattern, the 'CatWalk' automated quantitative gait analysis system was used (Noldus Ltd, version 7.1; Wageningen, The Netherlands). Animals were pre-trained before surgery and the pre-training values are included in the diagrams. This computer-assisted method of locomotor analysis made it possible to quantify several gait parameters, including duration and speed of different phases of the step cycle and print areas detected during locomotion length (Hamers et al., 2001, 2006). The following parameters were taken into account during the analysis:

the print area (expressed in $\left.\mathrm{mm}^{2}\right)$ : total floor area contacted by the paw during the stance phase, the print intensity (expressed in arbitrary units): the mean pressure exerted by one individual paw during the floor contact

the print width (expressed in $\mathrm{mm}$ ): parameters describing the width of the print area,

the stance duration (expressed in s): the stance duration is the time of the stance phase the swing speed (expressed in $\mathrm{m} / \mathrm{s}$ ): the swing speed is computed from swing duration and stride. 
the base of support of the hind limbs (BOS, expressed in $\mathrm{mm}$ ): The base of support of the hind limbs is the distance between the two hind paws of the rat.

\section{Statistical analysis}

The t-test and the two-way measurement analysis of variance (ANOVA) computed using Tukey's all pair-wise multiple comparison procedures, were used to compare the group data. The tests were used according to the nature of the data.

\section{Results}

\section{General observations, functional improvement, CatWalk gait analysis system}

Behavioral analysis was started two weeks after surgery and the first signs of functional recovery were observed 4-5 weeks after reimplantation of the ventral root. Control (group 1, reimplantation only) and group 2 animals (periradicular application of stem cells) showed minimal improvement, i.e. their affected hind limb was placed laterally with minimal dorsiflexion of the ankle joint and the spreading reflex was minimal or completely missing. In contrast, animals that received grafts into the L4 ventral root (group 3) or into the spinal cord (group 4) developed a movement pattern closely similar to that of the intact hind limb. Movements of the ankle joint, especially dorsiflexion was extensive and toe spreading was present. Quantitative gait analysis obtained from the CatWalk automated gait analysis system showed that the earliest differences in functional recovery between these groups appear from week 6 and these differences became significant by week 8- to 10 (Fig. 2). Improved footprint parameters (print area, intensity, print width, stance duration) in groups 3 and 4 indicated an improved stability of foot placing while parameters characteristic of the step cycle (swing speed and base of support of the hind limbs) showed improved movement pattern in 
group 3 and 4 animals (Fig 2), too. Interestingly, animals that received intraspinal or intraradicular stem cell grafts did not show significantly different gait parameters.

\section{Retrograde labelling studies, number of reinnervating motoneurons in various grafting protocols}

The number of retrogradely labelled motoneurons, i.e those motoneurones that were able to send their axons into the vacated endoneural sheaths of the reimplanted ventral root correlated with the functional data. Control animals that had their ventral root avulsed and reimplanted but received no stem cell graft had very few reinnervating cells (42 \pm 10 SEM). Similarly, in the spinal cords of group 2 animals which received a periradicular stem cell graft, more retrogradely labelled motoneurons were found $(65 \pm 2.5 \mathrm{SEM})$ but no significant difference was found between these two groups (Fig. 3). On the other hand, grafting of NE-GFP-4C cells into the reimplanted root (group 3) or into the spinal cord (group 4) produced similarly good results: the numbers of reinnervating cells were $671 \pm 26 \mathrm{SEM}$ and $711 \pm 14$ SEM, respectively (Fig. 3). It is noted, that the reinnervating cells in these two groups comprised 58 and $61 \%$ of the intact L4 motoneuron pool $(1158 \pm 14$ SEM), suggesting a very effective rescuing mechanism.

\section{Differentiation and location of grafted neuroectodermal cells}

The early differentiation and migration of the grafted cells was studied 5 and 10 days after grafting in animals that received stem cells intra- and periradicularly. The differentiation pattern of intraspinally grafted cells has been earlier described in our laboratory (submitted manuscript by Pajer et al.), therefore only brief details are given here.

Rats that received stem cell grafts embedded in fibrin clots and placed around the reimplanted ventral root, formed a well-defined tissue cuff around the reimplanted ventral root 5 days after grafting (Fig. 4A-D). The stem cells expressed the stage-specific embryonic antigen-1 (SSEA-1), 
an early murine stem cell marker (its expression is known to cease with differentiation) and most of them maintained their GFP expression. However, by 10 days after grafting most of the cells became dispersed and only few of them were found around the reimplanted root (Fig. 5A-B). At this stage of development, these cells expressed the M2 and M6 antigens, characteristic of mouse glial and neuronal phenotypes, respectively, but morphologically they remained rounded, and undifferentiated (Fig. 5A-B). In the animals that received intraradicular stem cell grafts, numerous NE-GFP-4C cells were found within the L4 ventral root 5 days after grafting (Fig. 4E-H). The cells formed clusters at the sites of injections and most of them were still able to express GFP. On the other hand, stem cells that expressed SSEA-1 displayed a decreased or faint GFP expression, suggesting that the GFP expression pattern decreases with differentiation (Fig. 4G-H). Ten days after grafting we found fewer grafted cells at the sites of microinjections and while most of the stem cells expressed SSEA-1, many of them were already able to differentiate to glial or neuronal phenotypes (M2+ astrocytes and M6+ neurons, Fig. 5D-E). Interestingly, those intraradicularly grafted cells that were placed close to the spinal cord were able to migrate closer to, but not into the injured cord via the reimplanted ventral root and started to differentiate morphologically, too (Fig. 5D-E). The intraspinal grafts formed a large cluster of cells that first expressed the SSEA-1 antigen and then further differentiated to M2+ astrocytes and M6+ neurons, respectively. Five days after grafting mainly SSEA-1+ cells were found in the graft (Fig. 4A-D), whereas by 10 days after grafting the presence of murine astrocytes and neurons was overwhelming (Fig. 5G-H). Parallel with the differentiation process the grafted cells ceased expressing GFP.

The first signs of axon outgrowth was also observed 10 days after reimplantation in these samples: few regenerating axons visualized by neurofilament (NF-200 kD) immunostaining were seen in the reimplanted root of animals that received intraradicular or intraspinal grafts of stem cells (Fig. 5F and 5I), while such regenerating neurites were infrequently seen in the reimplanted ventral root of animals with periradicularly grafted stem cells (Fig. 5C). Interestingly, several regenerating axons 
were found in this latter group among the derivatives of stem cells close to the reimplanted root (Fig. 5B).

Three months after grafting in the periradicularly treated animals (group 2) only few stem cellderived neurons and astrocytes were sporadically seen along the initial segment of the reimplanted root, typically in the dorsal angle between the reimplanted root and the lateral surface of the spinal cord (Fig. 6A-B). Greater numbers of stem cell-derived neurons and axons were found in the spinal segments of animals with intraradicular grafts (group 3). These cells were located mainly at the periphery of the root, not in close contact with the regenerated axons (Fig. 6D-E). Interestingly, a number of $\mathrm{M} 2+$ astrocytes and M6+ neurons appeared to have migrated into the ventral horn of the damaged L4 segment where these cells were located around the reimplanted root and the reinnervating motoneurons (Fig. 6D-E). Although many cells expressed M2 and M6 antigens on their membranes, only those cells appeared morphologically differentiated which settled in the spinal cord. The cells that stayed in the reimplanted root remained rounded and appeared morphologically undifferentiated while they expressed murine surface antigens characteristic of mature cells (Fig. 6D). In the spinal cords of animals that received stem cells intraspinally, relatively well-differentiated derivatives of stem cells were found, scattered throughout the L4 segment (Figure 6C).

\section{Discussion}

In this study we have provided evidence, that grafted embryonic neuroectodermal stem cells are able to rescue the vast majority of damaged motoneurons otherwise destined to die. However, rescue of injured motoneurons by grafted stem cells was only successful if the stem cells were placed into the affected segment of the spinal cord or into the reimplanted ventral root of animals whose L4 ventral root was avulsed to bring about motoneuron death. 
Adult motoneurons survive if their axons are damaged far from the cell body, but most of them die if the axonal injury is inflicted close to their soma. This latter type of injury is manifested in case of human brachial plexus injuries, where one or more ventral roots suffer traumatic avulsion due to harsh physical forces (Carlstedt 2008). Ventral root avulsion injuries can successfully be modelled in experimental animals and several experimental approaches have been reported to rescue motoneurons whose axons were avulsed. These experimental strategies are of outstanding importance as rescued motoneurons can be reconnected to their peripheral targets and this way improved reinnervation of denervated muscles can be achieved (Carlstedt and Cullheim 2000, Carlstedt 2008).

Earlier studies from have shown that stem or progenitor cells grafted into the spinal cord following avulsion and reimplantation of one or more spinal ventral roots are able to rescue damaged motoneurons (Hell et .2009, Su et al. 2009). Furthermore, it has also been shown that embryonic spinal cord grafts containing neural progenitors induce the survival of the injured motoneurons and also promote the growth of the regenerating motor axons into the reimplanted ventral root and then further along the peripheral nerves until motor fibres reach the skeletal muscles and produce functional reinnervation (Nógrádi and Szabó 2008, Nógrádi et al. 2011).

Grafting stem cells into the spinal cord or into the reimplanted ventral root resulted in equally good survival of injured motoneurons and functional reinnervation. It appears obvious that stem cells placed into the spinal cord are able to rescue motoneurons as they are very closely related to the motor pool of the affected segment and the paracrine mechanisms exerted by the graft have a direct effect on the affected ventral horn. On the other hand, transplanted cells in the reimplanted ventral root are not in the direct vicinity of the motor pool. It can be argued, however, that the amount of molecules secreted by the grafted stem cells was able to reach the intraspinal axon segment and the cell body of the injured motoneurons. The immunhistochemical analysis of the location and differentiation of the intraradicularly grafted cells showed that large numbers of stem cells were 
present 5 and 10 days after injury in the reimplanted root, closely related to the spinal cord and regrowing axons that were already present 10 days after avulsion. It could be noted that the distance between intraspinal grafts and the rostralmost part of the rescued L4 motoneuron pool is in fact not greater than that of an intraradicular graft and the rostral L4 motoneurons. It is thought that the diffusible factors produced by the grafts may reach the furthermost parts of the L4 segment, no matter whether they are secreted by an intraspinal or intraradicular graft. It has been reported that motoneurons after avulsion injury are responding to rescuing strategies if treatment starts within 10 days following avulsion (Nógrádi et al. 2007). Therefore it appears likely that appropriate numbers of stem cells located in the reimplanted ventral root were able to exert a motoneuron-rescuing effect similar to that found in the case of intraspinally grafted stem cells. Moreover, the stem cells did not migrate into the spinal cord within the first 10 days after grafting, thus their effect was exerted from their original location. It was a surprising finding, that stem cells grafted periradicularly (i.e. around the reimplanted root in a fibrin clot) induced as little reinnervation as spontaneously regenerating surviving L4 motoneurons in the control animals without receiving stem cells. The immunhistochemical analysis of the location of periradicularly placed stem cells showed that the stem cells and their derivatives were always in the close vicinity of the ventral root and and the L4 spinal segment but likely not close enough to the injured motor pool, therefore they could not exert a direct effect on the injured motoneurons, and/or injured motoneurons were not able to induce the paracrine secretion of of these cells. This view is further strengthened by results of the mapping of the stem cell-derived astrocytes and neurons in the treated spinal cords 3 months after grafting. While few hundreds of stem cell-derived glia- and neuron-like cells were found in the L4 segment of animals that received intraspinal and intraradicular stem cell grafts, no such cells could be located in animals treated with periradicular grafts. These findings suggest that stem cells were not able to migrate into the spinal cord from a periradicular location and as a consequence they were not close enough to the injured spinal motoneurons in the critical period of the first 10 days after 
avulsion and no satisfactory communication between the injured motor pool and the stem cell graft was established.

Transplantation of stem or neural progenitor cells (Hell et al. 2009, Su et al. 2009) producing neurotrophic factors or viral-based overexpression of BDNF or GDNF in the spinal cord or in the reimplanted ventral root (Blits et al. 2004, Eggers et al. 2008) induced prominent survival of damaged motoneurons with avulsed axons, but these rescued motoneurons were unable to send their axons into the reimplanted roots due to the enormous sprouting of regenerating axons. While the possible mechanisms of action are not discussed here, our preliminary data strongly suggest that the NE-GFP-4C stem cell line secretes factors that do not belong to the family of neurotrophic factors (our unpublished results).

In conclusion, it can be stated that stem cells that are able to rescue the vast majority of injured motoneurons destined to die following transplantation into the injured spinal cord segment are also able to induce the same effect if they are grafted into the reimplanted ventral root, close to the axons of the injured motor pool. These results suggest that the diffusible factors that modulate the environment of injured motoneurons are able to reach the ventral horn form more remote positions provided they are located still within the boundaries of the spinal cord and related spinal roots.

\section{Acknowledgements}

The authors are indebted to the Lorenz Böhler Fond for its generous support. 


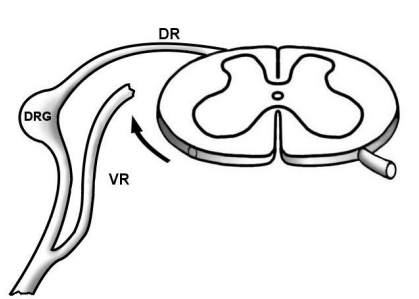

A

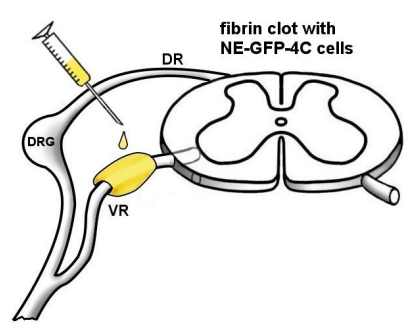

B: group 2

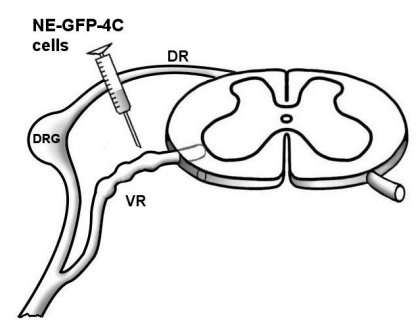

C: group 3

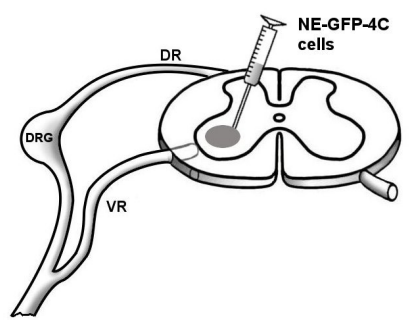

D: group 4

Figure 1. Schematic drawing depicting the various experimental paradigms

Three experimental surgical approaches are shown: After avulsion of the L4 ventral root (A) $3 \times 10^{5}$ stem cells were mixed in fibrin clot and applied around the reimplanted $\operatorname{root}(\mathbf{B}$, group 2). In other experimental groups stem cells were injected at three locations into the reimplanted root $(5 \mathrm{x} 10$ cells at each site, group 3, in C) or 3x10 ${ }^{5}$ cells were grafted into the spinal cord along with reimplantation of the avulsed root (D, group 4). 

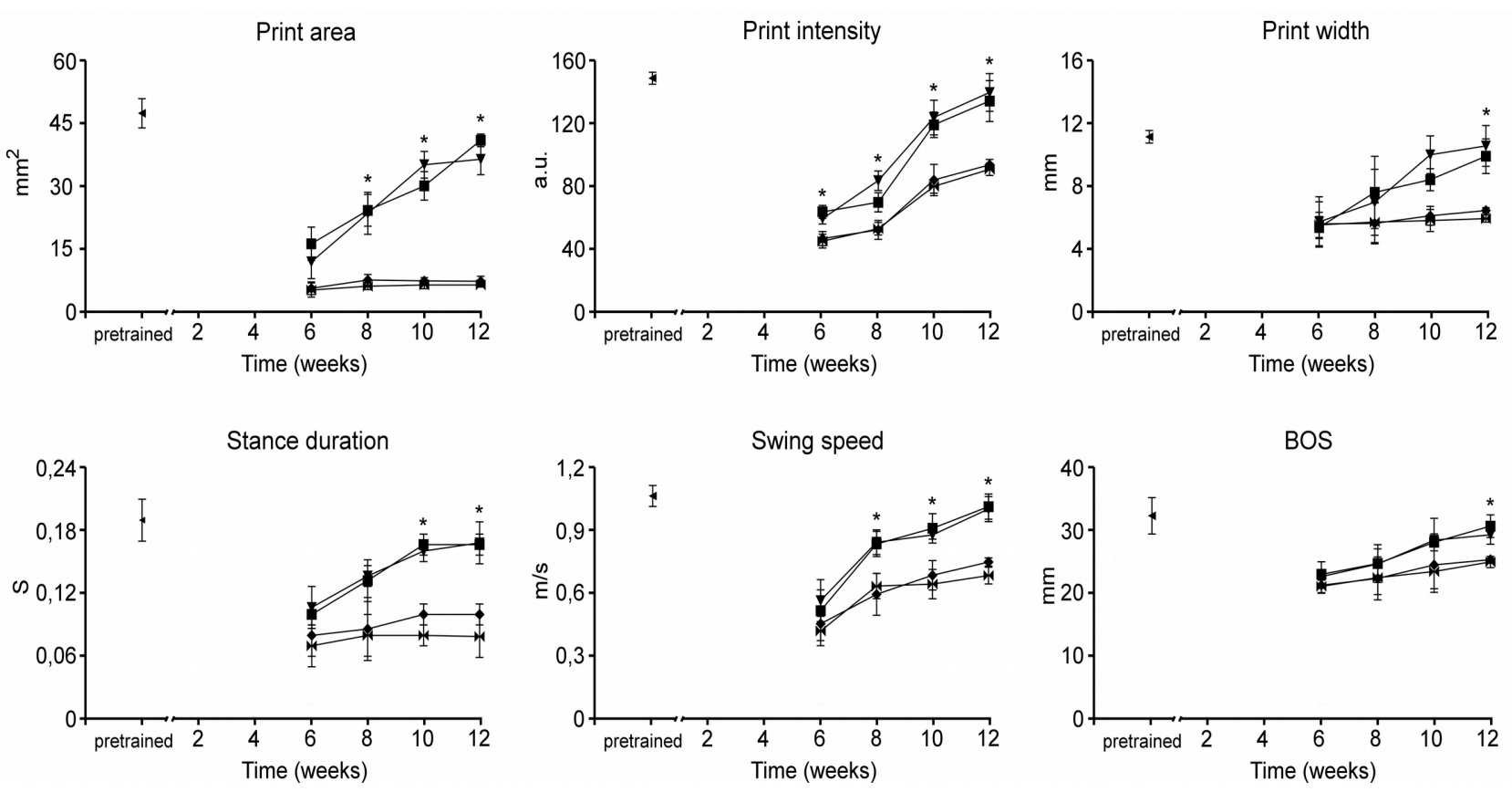

Figure 2. Results of the CatWalk automated gait analysis

The gait analysis revealed significant differences between groups 1,2 and 3,4. The earliest significant differences in functional recovery between these groups appeared from week 8 in case of some parameters. Both the parameters indicating improved stability of foot placing (print area, intensity, print width, stance duration) and that of improved step cycle (swing speed and base of support of the hind limbs) suggested significant functional reinnervation in group 3 and 4 animals. Note that the improved parameters of animals in groups 3 and 4 approached the pre-training levels. Asterisks indicate significant differences between groups 1,2 and 3,4 by using the two-way measurement analysis of variance (ANOVA) computed according to Tukey's all pair-wise multiple comparison procedures, $\mathrm{p}<0.05$. 


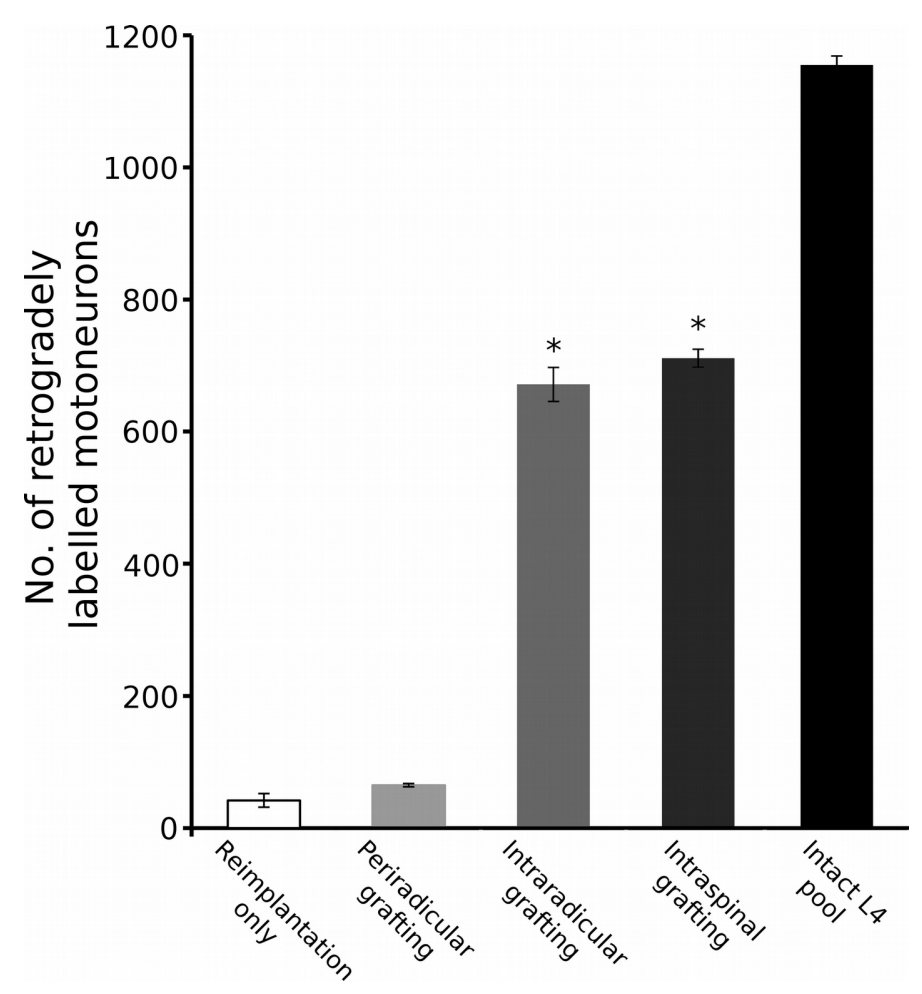

Figure 3. Bar chart showing the results of retrograde labelling studies from the L4 spinal nerve. Transplantation of stem cells into the reimplanted ventral root (group 3) or into the spinal cord (group 4) resulted in equally high numbers of retrogradely labelled motoneurons in the L4 segment (no significant difference was found between these groups). Transplantation of the stem cells around the reimplanted root (group 2) induced as limited reinnervation as reimplantation of the L4 root only (group 1, control animals). * = significant difference between groups 1, 2 and groups 3, 4, $\mathrm{p}<0.01$, t-test. 

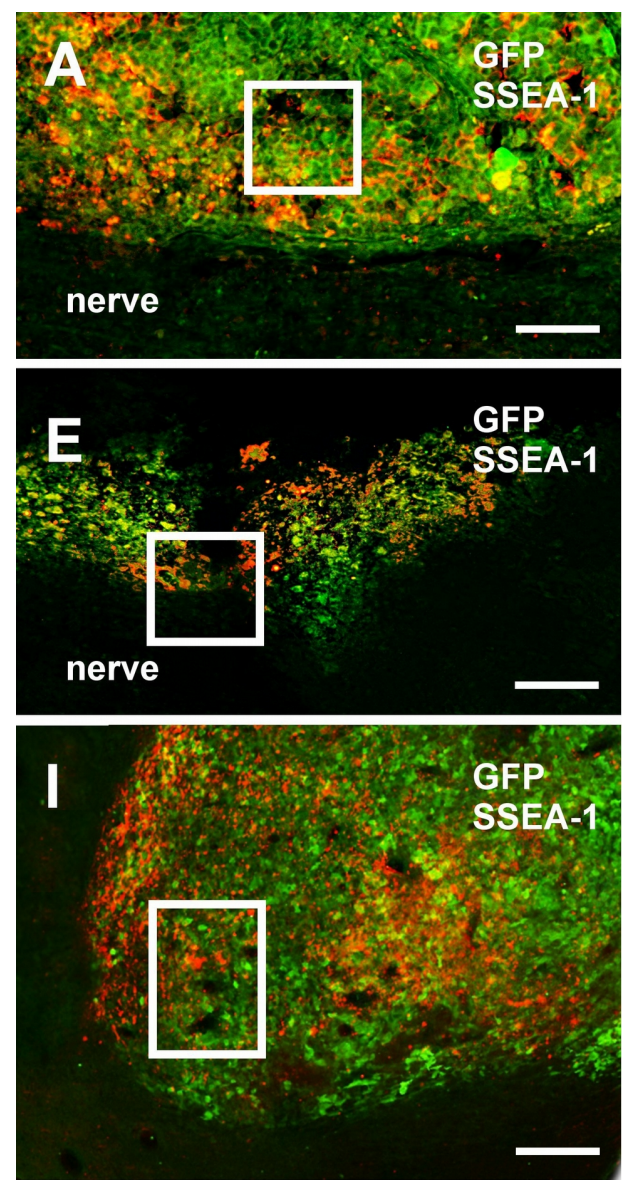
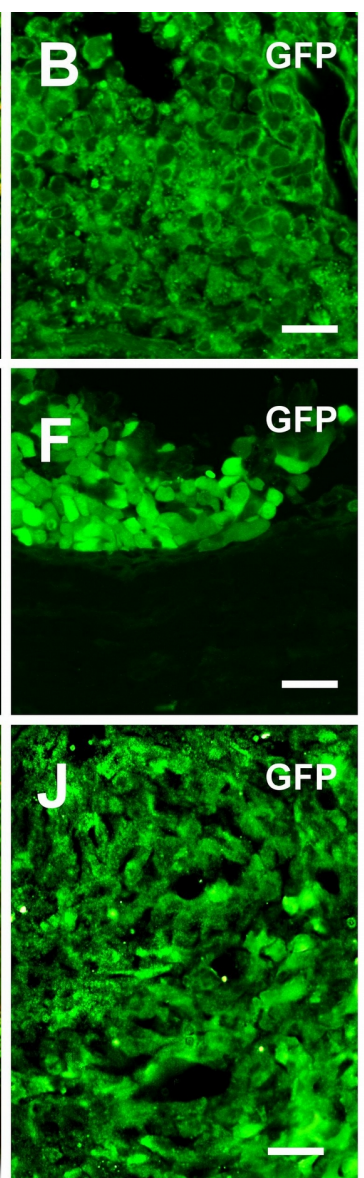
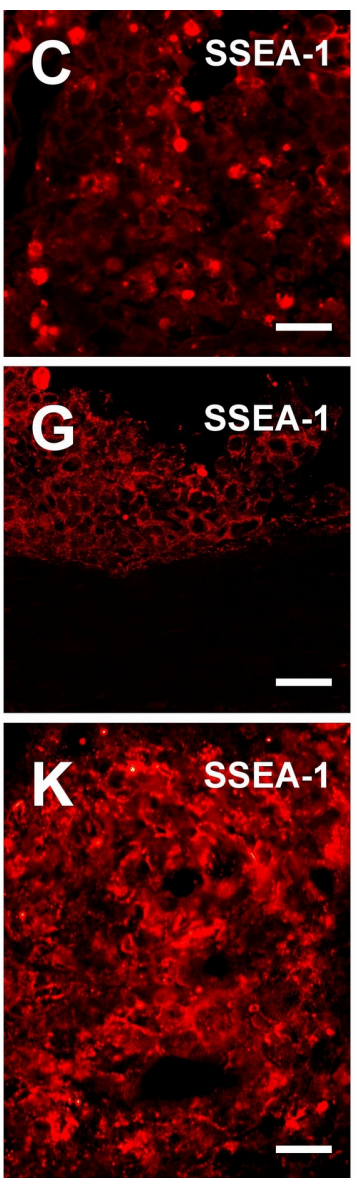
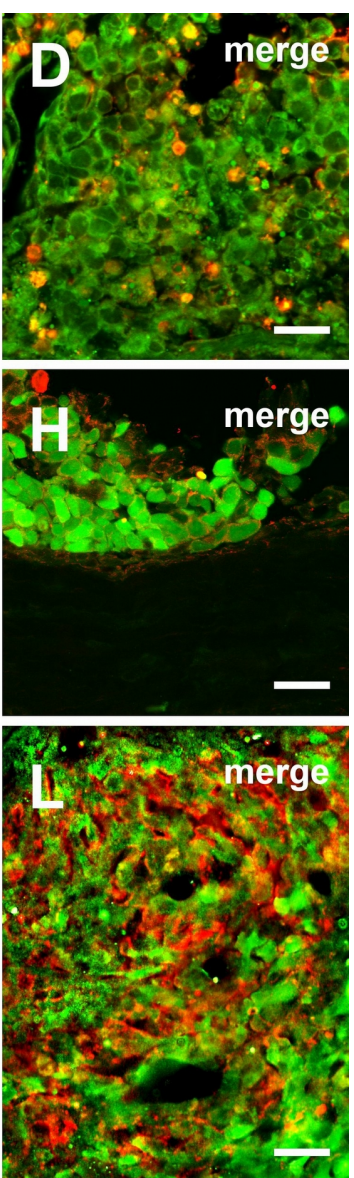

Figure 4. Location and differentiation of grafted stem cells in various experimental paradigms.

A-D shows differentiating NE-GFP-4C cells 5 days after transplantation around the reimplanted ventral root. The cells appear as a tissue mass outside the epineurium. E-H displays intraradicularly grafted stem cells just under the epineurium (not labelled) and I-L indicates the location and gene expression pattern of intraspinally grafted stem cells, in both cases 5 days after grafting. Note that the grafted GFP+ cells in all experimental paradigm express SSEA-1, a murine stage-specific stem cell marker. A-H are confocal images. Scale bar in A,E and I $=100 \mu \mathrm{m}$, in the rest of the figures $=20 \mu \mathrm{m}$. 

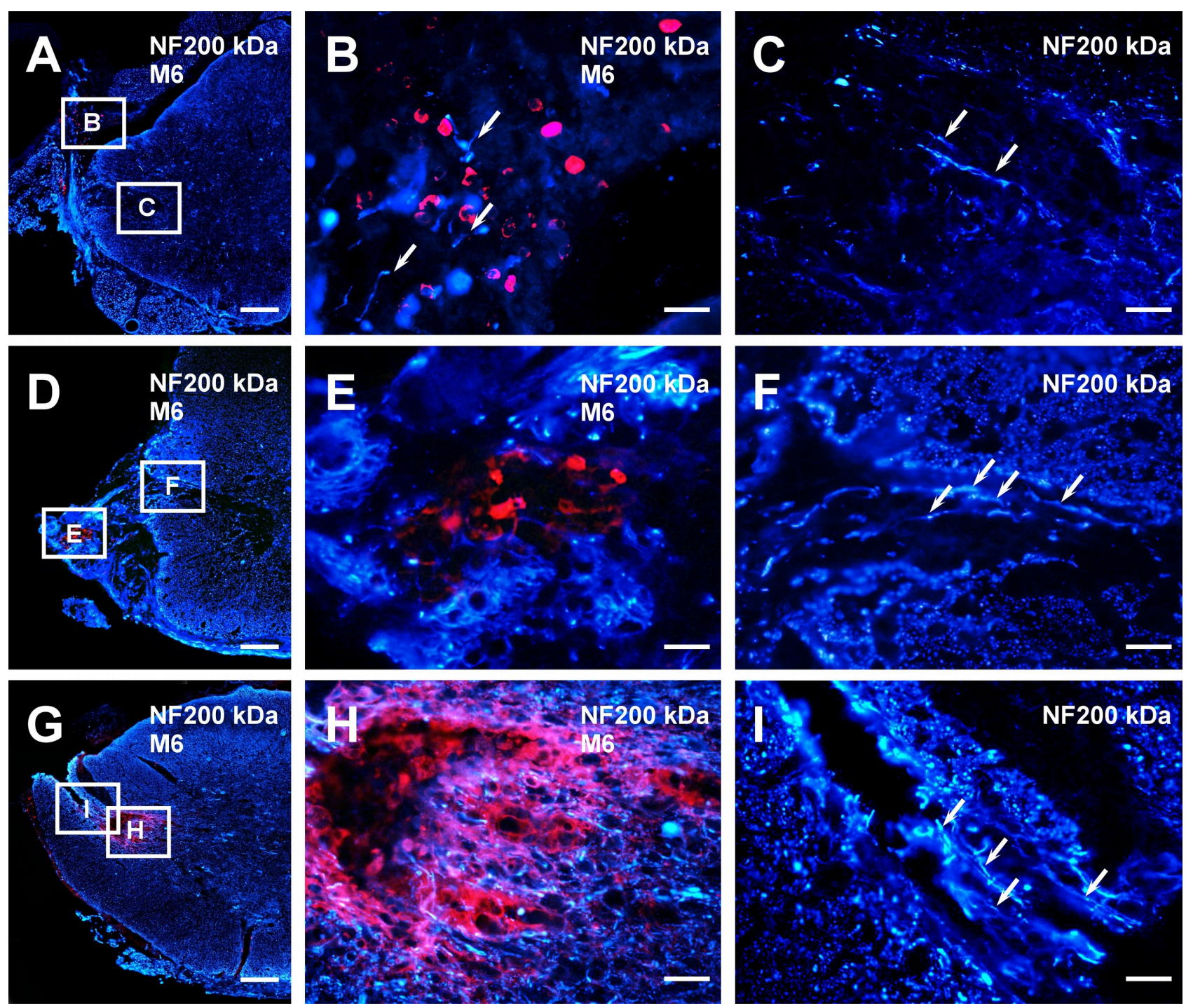

Figure 5. Outgrowth of regenerating axons from the ventral horn of the injured cord into the reimplanted root 10 days after grafting.

A shows a hemicord that received a periradicular stem cell graft (group 2, Neurofilament 200kDa immunohistochemistry - blue). Insets enlarged in $\mathbf{B}$ and $\mathbf{C}$ show the location of the $\mathrm{M} 6+$ grafted cells (red) within the ventral horn and the few NF200+ regenerating axons (arrows), respectively. Note the few axons (arrows) terminating around the surviving stem cells in $\mathbf{B}$. In $\mathbf{D}$ a section of a spinal cord is displayed with the reimplanted root, into which the stem cells were grafted (NF200 $\mathrm{kDa}$, group 3). $\mathbf{E}$ and $\mathbf{F}$ show the proximal injection site in the reimplanted root (E, M6 mouse neuronal marker, red), and the site of reimplantation with numerous regenerating axons (arrows in F, NF200 kDa immunohistochemistry). In G- to I microphotographs taken form intraspinally grafted animals are presented. Differentiating (M6 positive) stem cells (red) are located within the cord, at the end of the reimplanted ventral root $(\mathrm{G}$ and $\mathrm{H})$. Numerous NF200kDa+ axons (blue and indicated by arrows) entered the reimplanted root. Scale bar in $A, D$ and $G=100 \mu \mathrm{m}$, in the rest of the figures $=20 \mu \mathrm{m}$. 

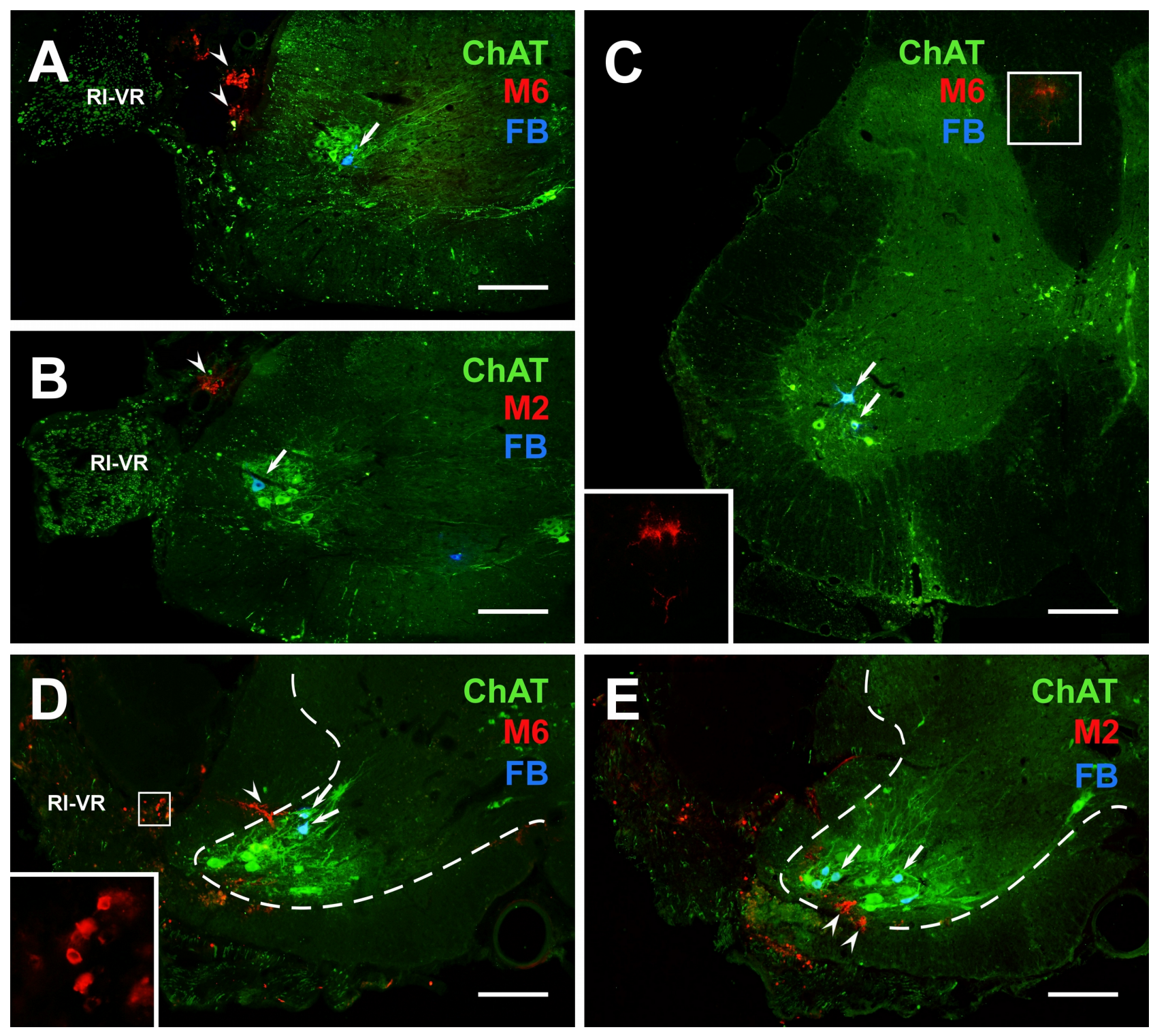

Figure 6. Localization of the derivatives of the grafted stem cells in various experimental paradigms

$\mathbf{A}$ and $\mathbf{B}$ show sections of the spinal cord (group 2, periradicular grafting) taken at the level where the reimplanted root (RI-VR) is closely apposed to the cord. The few retrogradely labelled motoneurons (arrows, Fast Blue+, FB) colocalise with the numerous surviving ChAT + motoneurons (green) in the ventral horn. Few surviving undifferentiated cells (arrowheads, M6+ neurons in $\mathbf{A}$ and $\mathrm{M} 2+$ astrocytes in $\mathbf{B}$ ) settled in the dorsal angle between the reimplated L4 root and the dorsolateral surface of the cord. $\mathbf{C}$ shows surviving (ChAT+, green) and reinnervating (Fast Blue+, blue) motoneurons (arrows) in the ventral horn and stem cell-derived -like cells in the dorsal funiculus of an animal that received intraspinal stem cell graft (group 4). Inset provides high magnification view of the M6+ cells. $\mathbf{D}$ and $\mathbf{E}$ display sections taken from intraradicularly grafted animals (group 3). Note the greater numbers of retrogradely labelled motoneurons (arrows)within the pool of surviving motoneuron pool (ChAT+, green), Stem cell-derived rounded astrocytes and neurons are present in the reimplanted ventral root (RI-VR, see inset for higher magnification in $\mathbf{D}$ ), 
however, many of these cells migrated into the affected ventral horn and took up a more differentiated morphological phenotype (arrowheads, M6+ and M2+ cells shown in D and E, respectively). Scale bar $=200 \mu \mathrm{m}$. 


\section{REFERENCES}

Blits, B., Carlstedt, T.P., Ruitenberg, M.J., De Winter, F., Hermens, W.J., Dijkhuizen, P.A., Classens, J.W.C., Eggers, R., van der Slius, R., Tenenbaum, L., Boer, G.J. and Verhaagen, J. (2004). Rescue and sprouting of motoneurons following ventral root avulsion and reimplantion combined with intraspinal adeno-associated viral vector mediated expression of glial cell line derived neurotrophic factor or brain derived neurotrophic factor. Exp Neurol, 189, 303-331.

Bottai, D., Cigognini, D., Madaschi, L., Adami, R., Nicora, E., Menarini, M., di Giulio, A.M. and Gorio, A. (2010). Embryonic stem cells promote motor recovery and affect inflammatory cell infiltration in spinal cord injured mice. Exp Neurol, 223, 452-463.

Carlstedt, T.P. (2008). Root repair review: Basic science background and clinical outcome. Rest Neurol Neurosci, 26, 225-241.

Carlstedt, T.P. and Cullheim, S. (2000). Spinal cord motoneuron maintenance, injury and repair. Prog Brain Res, 127, 501-514.

Carlstedt, T.P., Hallin, R.G., Hedström, K.G. and Nilsson-Remahl, I.A. (1993). Functional recovery in primates with brachial plexus injury after spinal cord implantion of avulsed ventral roots. J Neurol Neurosurg \& Psych, 56, 649-654.

Eggers, R., Hendriks, W.T.J., Tannemaat, M.R., van Heerikhuize, J.J., Pool, C.W., Carlstedt, T.P., Zaldumbide, A., Hoeben, R.C., Boer, G.J. and Verhaagen, J.(2008). Neuroregenerative effects of lentiviral vector-mediated GDNF expression in reimplanted ventral roots. Mol Cell Neurosci, 39, 105-117.

Eggers, R., Tannemaat, M.R., Ehlert, E.M. and Verhaagen, J. (2010). A spatio-temporal analysis of motoneuron survival, axonal regeneration and neurotrophic factor expression after lumbar ventral root avulsion and implantation. Exp Neurol, 223, 207-220.

Hádinger, N., Varga, B.V., Berzsenyi, S., Környei, Z., Madarász, E. and Herberth, B. (2009) Astroglia genesis in vitro: distinct effects of retinoic acid in different phases of neural stem cell differentiation. Int J Dev Neurosci, 27, 365-75.

Hamers, F.P.T., Lankhorst, A.J., van Laar, T.J., Veldhuis, W.B. and Gispen, W.H. (2001). Automated quantitative gait analysis during overground locomotion in the rat: its application to spinal cord contusion and transection injuries. J Neurotrauma, 18, 187-201.

Hamers, F.P.T., Koopmans, G.C. and Joosten, E.A.J. (2006). Catwalk-assisted gait analysis in the assessment of spinal cord injury. J Neurotrauma, 23, 537-548.

Haninec, P., Houštava, L., Stejskal, L. and Dubový, P. (2003). Rescue of rat spinal motoneurons from avulsion-induced cell death by intrathecal administration of IGF-I and cerebrolysin. Ann Anat, 185, 233-238. 
Hell, R.C.R., Costa, M.M.S., Goes, A.M. and Oliveira, A.L.R. (2009). Local injection of BDNF producing mesenchymal stem cells increases neuronal survival and synaptic stability following ventral root avulsion. Neurobiol Dis, 33, 290-300.

Koliatsos, V.E., Price, W.L., Pardo, C.A. and Price, D.L. (1994). Ventral root avulsion: an experimental model of death of adult motor neurons. J Comp Neurol, 342, 35-44.

Nógrádi, A., Pajer, K. and Márton, G. (2011). The role of embryonic of embryonic motoneuron transplants to restore the lost motor function of the injured spinal cord. Ann Anat, 193, 362-370.

Nógrádi, A. and Szabó, A. (2008). Transplantation of embryonic neurones to replace missing spinal motoneurones. Rest Neurol Neurosci, 26, 215-223.

Nógrádi, A., Szabó, A., Pintér, S. and Vrbová, G. (2007). Delayed riluzole treatment is able to rescue injured spinal motoneurons. Neuroscience 144, 431-438.

Nógrádi, A. and Vrbová, G. (1996). Improved motor function of denervated rat hindlimb muscles by embryonic spinal cord grafts. Eur J Neurosci, 8, 2198-2203.

Nógrádi, A. and Vrbová, G. (2001). The effect of riluzole in rats on the survival of injured adult and grafted embryonic motoneurones. Eur J Neurosci, 13, 113-118.

Novikov, L., Novikova, L. and Kellerth, J.O. (1995). Brain-derived neurotrophic factor promotes survival and blocks nitric oxide synthase expression in adult rat spinal motoneurons after ventral root avulsion. Neurosci Lett, 200, 45-48.

Pintér, S., Gloviczki, B., Szabó, A., Márton, G. and Nógrádi, A. (2010). Increased survival and reinnervation of cervical motoneurons by riluzole following avulsion of the $\mathrm{C} 7$ ventral root. $\mathrm{J}$ Neurotrauma, 27, 2273-2282.

Ruff, C.A., Wilcox, J.T. and Fehlings, M.G. (2012) Cell-based transplantation strategies to promote plasticity following spinal cord injury. Exp Neurol, 235, 78-90.

Schlett, K., Herberth, B. and Madarász, E. (1997). In vitro pattern formation during neurogenesis in neuroectodermal progenitor cells immortalized by p53-deficiency. Int J Devl Neurosci, 15, 795-804.

Steinbeck, J.A., Koch, P., Derouiche, A. and Brustle, O. ( 2012) Human embryonic stem cellderived neurons establish region-specific, long-range projections in the adult brain. Cell Mol Life Sci, 69, 461-470.

Su, H., Zhang, W., Guo, J., Guo, A., Yuan, Q. and Wu, W. (2009). Neural progenitor cells enhance the survival and axonal regeneration of injured motoneurons after transplantation into the avulsed ventral horn of adult rats. J Neurotrauma, 26, 67-80.

Wu, W., Li, L., Yick, L.W., Xie, Y., Yang, Y., Prevette, D.M. and Oppenheim, R.W. (2003). GDNF and BDNF alter the expression of neuronal NOS, c-Jun, and p75 and prevent motoneuron death following spinal root avulsion in adult rats. J Neurotrauma, 20, 603-612. 